\title{
PRODUCTION OF FURFURAL FROM OIL PALM FIBRES
}

\begin{abstract}
NUR ELIYANTI ALI OTHMAN ${ }^{1 *}$; ASTIMAR ABD AZIZ1; WAN HASAMUDIN WAN HASSAN ${ }^{1}$; NOR FAIZAH JAILANI ${ }^{1}$; FAZLIANA ABD HAMID ${ }^{1}$ and NOORSHAMSIANA ABDUL WAHAB ${ }^{1}$
\end{abstract}

\begin{abstract}
Furfural is a chemical compound produced by biomass rich in pentoses content in the hemicellulose as raw material, in a reaction catalysed in presence of strong acids. This study determines the process parameters for converting xylan, extracted from oil palm empty fruit bunches (OPEFB), into furfural using a two-step process, namely acid hydrolysis, followed by dehydration. Xylan was first extracted from OPEFB using direct alkaline extraction method. The resulting xylan was then treated with a known concentration of sulphuric acid $\left(\mathrm{H}_{2} \mathrm{SO}_{4}\right.$ ) (ranging from $11 \%-15 \% \mathrm{v} / \mathrm{v}$ ) with reaction time (ranging from 30-150 min), with or without presence of sodium chloride $(\mathrm{NaCl})$ as co-catalyst to produce xylose. After dehydration process, xylose was converted into furfural with parameters as in dehydration process. Furfural was characterised using Fourier transform infrared (FTIR) and Proton nuclear magnetic resonance $\left({ }^{1} H-N M R\right)$. FTIR spectrum exhibited a very strong absorption at $1706 \mathrm{~cm}^{-1}$, indicating the presence of the conjugated carbonyl $(C=O)$ group. The highest yield of furfural produced was 9.01\% after treatment with $15 \% \mathrm{H}_{2} \mathrm{SO}_{4}$ using $\mathrm{NaCl}$ as catalyst for $90 \mathrm{~min}$. However, pentosans only contribute a portion of the total composition of lignocellulose, compared to cellulose which is the largest fraction of lignocellulosic biomass. Therefore, the furfural should be extracted using an integrated value economy method.
\end{abstract}

Keywords: dilute acid hydrolysis, empty fruit bunch fibre, furfural.

Received: 13 August 2020; Accepted: 12 October 2020; Published online: 9 December 2020.

\section{INTRODUCTION}

Furfural or 2-furaldehyde and its derivatives are considered as a versatile precursor to obtain a wide range of chemicals for various applications (Kamm et al., 2006; Alonso-Fagundez et al., 2012; Sadaba et al., 2011; Mansilla et al., 1998). The furfuryl alcohol produced from hydrogenation of furfural has been used as additive or solvent in the production of resins with different characteristics in chemical industry (Merlo et al., 2009; Vazquez et al., 2007; Mansilla et al., 1998). One of the common and important usage of furfural in gas oil, diesel fuel and petroleum refining industry is as selective solvent for separating saturated and unsaturated compounds (Mansilla et

\footnotetext{
Malaysian Palm Oil Board,

6 Persiaran Institusi, Bandar Baru Bangi,

43000 Kajang, Selangor, Malaysia.

* Corresponding author e-mail: nureliyanti@mpob.gov.my
}

al., 1998). In addition, furfural along with its sister molecule, hydroxymethyl furfural (HMF) can serve as a building block for other potential transportation fuels, including dimethylfuran and ethyl levulinate. These fuels could replace furan from petroleum based maleic anhydride (Shen et al., 2018).

Furfural is produced by acid hydrolysis process and dehydration of pentoses containing (mainly xylose) in lignocellulosic materials. Figure 1 shows simplified reaction scheme for conversion of lignocellulosic biomass into furfural. Several researchers investigated the production of furfural by hydrolysis of lignocellulosic waste materials in dilute acid, such as hydrochloric acid (Herrera et al., 2004; 2003; Lavarack et al., 2002) nitric acid (Rodriguez-Chong et al., 2004), sulphuric acid $\left(\mathrm{H}_{2} \mathrm{SO}_{4}\right)$ (Yat et al., 2008; Rahman et al., 2006; Aguilar et al., 2002; Montane et al., 2002) and phosphoric acid (Lenihan et al., 2010; Vazquez et al., 2007; Gamez et 
al., 2006). The advantage of acid hydrolysis is that the rate of acid hydrolysis is faster than enzyme hydrolysis but glucose also degrades rapidly under acidic conditions (Cheung and Anderson, 1996).

Acid hydrolysis employs usually $\mathrm{H}_{2} \mathrm{SO}_{4}$ and hydrochloric acid at concentrations of 1\%-15\% using moderate temperature (in the range of $100^{\circ} \mathrm{C}-150^{\circ} \mathrm{C}$ ) (Wingren et al., 2003). Dilute acid hydrolysis is generally more desirable compared to concentrated acid because of its lower cost. It also allows the high degradation of lignocellulosic biomass under relatively low reaction temperatures. The $\mathrm{H}_{2} \mathrm{SO}_{4}$ and hydrochloric acids are the most commonly used catalysts for hydrolysis of lignocellulosic biomass.

The formation of furfural from pentosan can be understood in terms of hydrolysis of pentosan (xylan), followed by dehydration of pentose (xylose). Introduction of water molecule in hydrolysis process is to break the glycosidic bond to form xylose or arabinose, and later in dehydration process, three water molecules are then released from the respective sugars to form furfural. Figure 2 shows acid hydrolysis and dehydration process of xylose for furfural production.

Several mechanisms have been proposed for furfural formation from xylan. Nimlos et al. (2006) favoured closed-chain formation of a dehydrofuranose intermediate by ring contraction of the O2-protonated pyranose (Figure 3) in the presence of strong acid such as $\mathrm{H}_{2} \mathrm{SO}_{4}$.

Furfural can be extracted from lignocellulosic materials, including plant fibre, such as eucalyptus (García-Domínguez et al., 2013), olive tree (Romero et al., 2010), agriculture waste such as rice husks (Suxia et al., 2012), corn cobs (Sánchez et al., 2013), sorghum straw (Vazquez et al., 2007), sugar cane bagasse (Gamez et al., 2006), wheat straw (Yemis and Mazza, 2011) rice straw (Lin et al., 2013) and non-wood fibre such as date palm tree (Bamufleh et al., 2013). For non-wood, the study on the conversion of oil palm fibre into furfural was limited. About $17.34 \%$ furfural was produced from oil palm mesocarp fibre when it was subjected to $15 \% \mathrm{H}_{2} \mathrm{SO}_{4}$ (Riansa-Ngawong and Prasertsan, 2011).

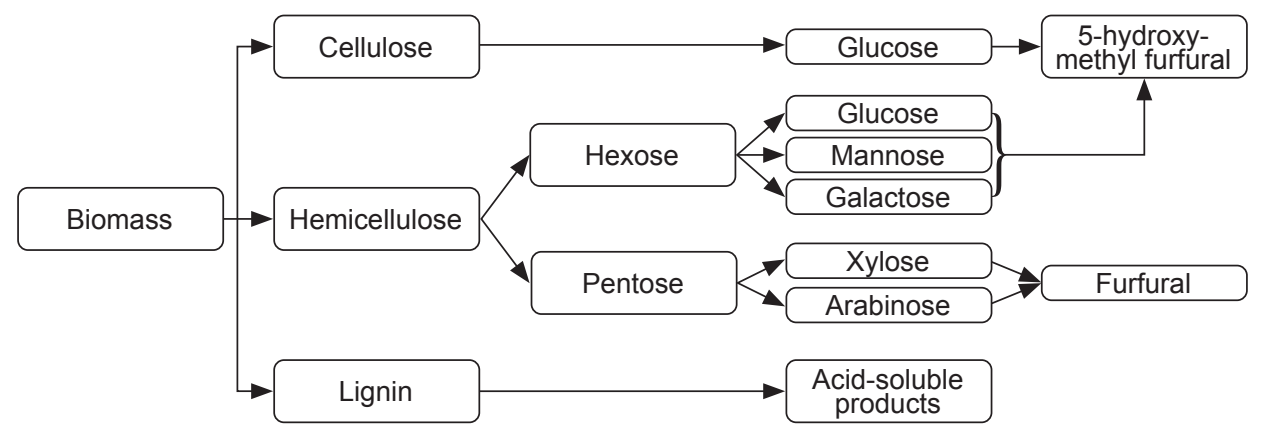

Figure 1. Simplified reaction scheme for conversion of lignocellulosic biomass to furfural.

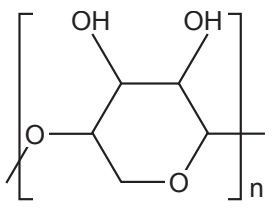

(a)

a)

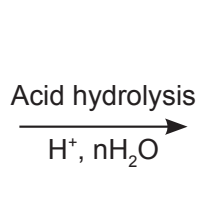

(1)

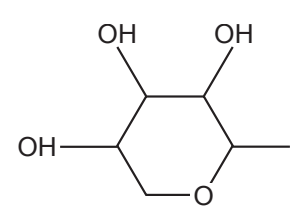

(b)

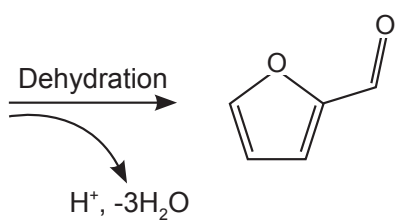

(c)

Source: Riansa-Ngawong and Prasertsan (2011).

Figure 2. (a) Hydrolysis of pentosan (b) followed by dehydration of pentose, (c) to form furfural.

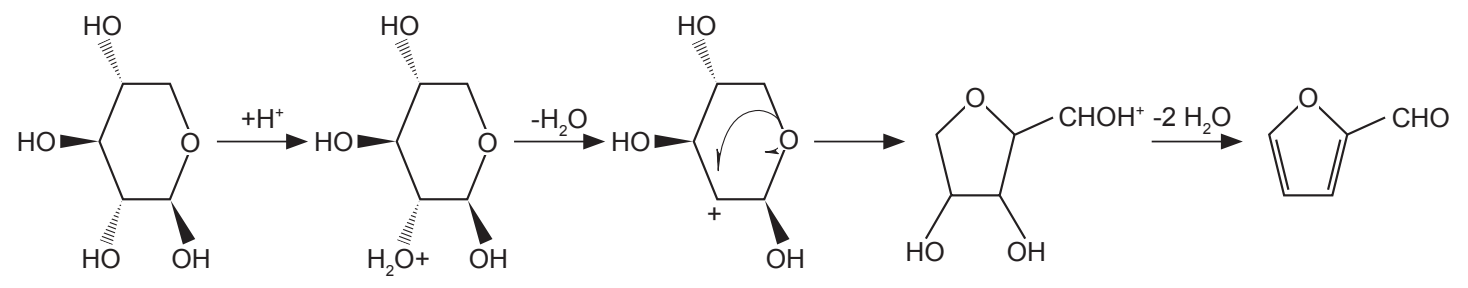

Figure 3. Proposed closed-chain mechanism for furfural formation from xylose. 
It is estimated about one third of total pentosans (raw material) can be converted into furfural by existing production processes (Mansilla et al., 1998). In theory, any material containing a large amount of pentose (five carbon) sugars arabinose and xylose can serve as raw material for furfural production. Table 1 outlines the approximate pentosan content of several plants and agricultural residues potentially suitable for furfural production.

In Malaysia, from $17.16 \mathrm{t} \mathrm{ha}^{-1}$ of oil palm fresh fruit bunches produced in 2018, the oil palm industry generates 20\%-22\% oil palm empty fruit bunches (OPEFB) (Kushairi et al., 2019). The OPEFB biomass with cellulose, hemicelluloses and lignin is estimated to contain about $23 \%-26 \%$ xylan, a sugar polymer made of pentose sugar, xylose (Rahman et al., 2006). Studies available on furfural production from oil palm tree wastes are scarce, relatively old and limited in scope (Rahman et al., 2006; RiansaNgawong and Prasertan 2010; 2011; Loi et al., 2011).

The aim of this work is to investigate the production of furfural from OPEFB using $\mathrm{H}_{2} \mathrm{SO}_{4}$ as catalyst for the process and sodium chloride $(\mathrm{NaCl})$ will be introduced as a co-catalyst or promoter. The effect of acid concentration and reaction time will be investigated and the optimum condition to maximise furfural yield will be determined.

TABLE 1. PENTOSAN CONTENT OF PLANTS AND AGRICULTURAL RESIDUES

\begin{tabular}{lc}
\hline Plant material & $\begin{array}{c}\text { Pentosan } \\
\text { content }(\%)\end{array}$ \\
\hline Corn cobs & 35 \\
Almond husks & 30 \\
Rye straw & 30 \\
Oat hulls & 29 \\
Cottonseed hulls & 28 \\
Barley straw & 25 \\
Birchwood residues after felling & 25 \\
Sugarcane bagasse & 25 \\
Sunflower husks & 25 \\
Wheat straw & 24 \\
Flax shives & 23 \\
Hazelnut shells & 23 \\
Birchwood logs & 22 \\
Eucalyptus wood & 20 \\
Rice hulls & 17 \\
Maple wood & 16 \\
Pinewood & 8 \\
Peanut shells & 3 \\
\hline
\end{tabular}

Source: O’Brien (2006).

\section{METHODOLOGY}

\section{Materials}

Shredded OPEFB fibres were collected from the Palm Oil Milling Technology Centre (POMTEC), located in Labu, Negeri Sembilan, Malaysia. After drying, OPEFB fibres were kept in a plastic bag and stored at room temperature. All chemicals used were analytical grade and used without further purification. Xylan from beech wood and 2-furfuraldehyde (furfural) standard reference materials were purchased from Sigma-Aldrich.

\section{Method}

OPEFB pretreatment and xylan extraction. Pretreatments of OPEFB fibres were carried out according to ASTM D 1104-56 (1978). Dry EFB-fibre was initially treated by soaking in $24 \%$ solution sodium chlorite $\left(\mathrm{NaClO}_{2}\right)$ in the ratio of $1: 10(\mathrm{w} / \mathrm{v})$ and $(\mathrm{ml}) 0.01 \%$ acetic acid solution, at $70^{\circ} \mathrm{C}$ for $1 \mathrm{hr}$. The solid residues were then washed with hot water followed by acetone, to remove water. The treated OPEFB fibres was then dried in an electric oven at $105^{\circ} \mathrm{C}$ for $3 \mathrm{hr}$.

The treated OPEFB fibres were then soaked in $3 \mathrm{M}$ sodium hydroxide $(\mathrm{NaOH})$ at ratio of 1:10 $(\mathrm{w} / \mathrm{v})$ for $4 \mathrm{hr}$. The solid residue material was then separated from the solution by vacuum filtration. The filtrate was collected and neutralised with $50 \%$ acetic acid $(\mathrm{v} / \mathrm{v})$. Cold isopropanol was then slowly mixed into the filtrate admixture resulting in a colloidal suspension. After being left overnight, the suspension was then separated into two heterogenous layers containing xylan solid. After filtration, the xylan was washed with $100 \mathrm{ml}$ distilled water and dried in an electric oven at $60 \pm 5^{\circ} \mathrm{C}$ for $6 \mathrm{hr}$. The yield (\%) of xylan was measured as dry weight basis and calculated using the following Equation (1):

$$
\text { Yield }(\%)=\frac{\text { Weight of dried xylan }}{\text { Weight of dried OPEFB }} \times 100
$$

Conversion of xylan into furfural. Furfural was converted from xylan using a modified steam distillation method (Sashikala and Ong, 2007). About $1 \mathrm{~g}$ dry xylan was placed into a $250 \mathrm{ml}$ round bottomed flask with $100 \mathrm{ml}$ of dilute $\mathrm{H}_{2} \mathrm{SO}_{4}$. The mixture was constantly stired and heated at $175^{\circ} \mathrm{C}$. The vapour produced was condensed and collected in a receiving flask. The distillation process ran for 30-150 min.

Characterisation of xylan and furfural. The extracted xylan was characterised using Fourier transform infrared (FTIR) spectroscopic technique. Furfural was also characterised using FTIR and Proton nuclear 
magnetic resonance $\left({ }^{1} \mathrm{H}-\mathrm{NMR}\right)$. FTIR analysis was performed by Perkin Elmer TG-IR Hyphenation System and ${ }^{1} \mathrm{H}-\mathrm{NMR}$ spectra were obtained using JEOL ECZ 600R/S1 spectrometer. The ${ }^{1} \mathrm{H}-\mathrm{NMR}$ spectra were measured at $600.17 \mathrm{MHz}$ in deuterium oxide $\left(\mathrm{D}_{2} \mathrm{O}\right)$.

Amount of furfural in distillate was determined by Ultraviolet visible (UV-Vis) spectroscopy, as furfural has a strong absorption in ultra violet at wavelength of $276 \mathrm{~nm}$ (Zhang et al., 2017). The concentration of furfural can be calculated from the calibration graph of commercial furfural. The calibration graph of commercial furfural was obtained based on absorption spectrum of a set of different concentrations at $276 \mathrm{~nm}$. The UV-Vis spectroscopy was carried out using a Thermo Scientific Genesys $10 \mathrm{~S}$ UV-Vis (Figure 4).

\section{RESULTS AND DISCUSSION}

\section{Characterisation of Xylan by FTIR Spectroscopy}

The xylan yield was about 22\%-25\% per $\mathrm{kg}$ of EFB-fibre processed. From FTIR spectroscopy analysis, spectrum of xylan from EFB was found to be comparable to that of standard commercial xylan (Sigma).

The FTIR spectrum of xylan from OPEFB within the region of $650-4000 \mathrm{~cm}^{-1}$ is shown in Figure 5. The region of between $850-1200 \mathrm{~cm}^{-1}$ is typical for hemicellulose. This indicates that the alkaline extraction did not change the macromolecular structure of xylan. The absence of absorption band at $1710 \mathrm{~cm}^{-1}$ which is the finger-print peak for carboxyl groups in lignin, showed that the extracted xylan was pure and clean from lignin residue (Herrera et al., 2003).

Absorption band at $1037 \mathrm{~cm}^{-1}$ was due to the $\mathrm{C}-\mathrm{O}-\mathrm{C}$ stretching glycosidic linkages in xylan. The broad absorption band at 3400 and $2400 \mathrm{~cm}^{-1}$ were due to the stretching vibrations of $\mathrm{OH}$ and $\mathrm{C}-\mathrm{H}$ respectively. The $\mathrm{C}-\mathrm{H}$ bending vibration showed absorption bands at 1555 and $1406 \mathrm{~cm}^{-1}$ while the $\mathrm{OH}$ bending vibration showed absorption bands at $1344 \mathrm{~cm}^{-1}$.

\section{Characterisation of Furfural by FTIR Spectroscopy}

The furfural obtained was in liquid form. It was colourless intially but turned yellowish to dark brown when exposed to light and air. Its scent resembled that of bitter almond. Its vapour irritates the eyes. Figure 6 shows an overlay FTIR spectra of xylan and furfural from OPEFB.

The FTIR spectrum of furfural showed a very strong absorption at $1706 \mathrm{~cm}^{-1}$. This absorption indicates a very significant functional group in furfural which is the conjugated carbonyl $(\mathrm{C}=\mathrm{O})$ (Sashikala and Ong, 2007). The absorption wave number was slightly lower than usual, which is around $1740-1720 \mathrm{~cm}^{-1}$, due to internal hydrogen bonding that occurs in conjugated unsaturated aldehydes. However, this peak can be atributed to chemical compounds such as carboxylic acid $(\mathrm{COOH})$, ketone, ester and aldehyde groups. The absence of peak at $1725 \mathrm{~cm}^{-1}$ strongly indicates the presence of aldehyde and not ketone group. Furthermore, no broad peak is observed between $3400-2400 \mathrm{~cm}^{-1}$ of hydroxyl $(\mathrm{OH})$, as in xylan FTIR spectrum. This confirmed the absence of carboxylic acid group. The presence of aldehyde was proven with the existence of two peaks at $2841 \mathrm{~cm}^{-1}$ and $2816 \mathrm{~cm}^{-1}$ respectively. These absorptions showed moderate intense stretching of aldehydic $\mathrm{C}-\mathrm{H}$, attributed to the resonance between stretching and bending vibration of aldehydic $\mathrm{C}-\mathrm{H}$, which appeared at $1389 \mathrm{~cm}^{-1}$ in the spectrum. These bands were observed in aldehyde group.

Strong peaks between $1565-1466 \mathrm{~cm}^{-1}$ represent stretching of $\mathrm{C}=\mathrm{C}$ from aromatic ring. Aromatic $=\mathrm{C}-\mathrm{H}$ bending out of plane peaks were observed from 929-881 $\mathrm{cm}^{-1}$. Two strong peaks at $1016 \mathrm{~cm}^{-1}$ and $1077 \mathrm{~cm}^{-1}$ indicated the C-O stretching vibration. This FTIR spectrum was comparable to commercial furfural standard reference material FTIR spectrum.

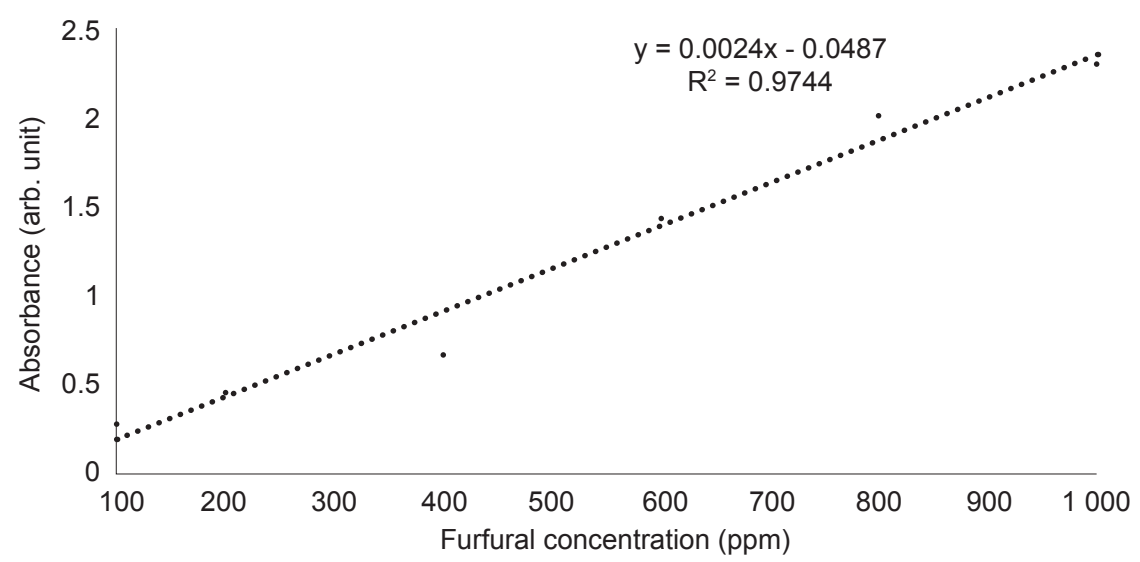

Figure 4. Calibration graph of standard commercial furfural in distilled water at different concentration. 


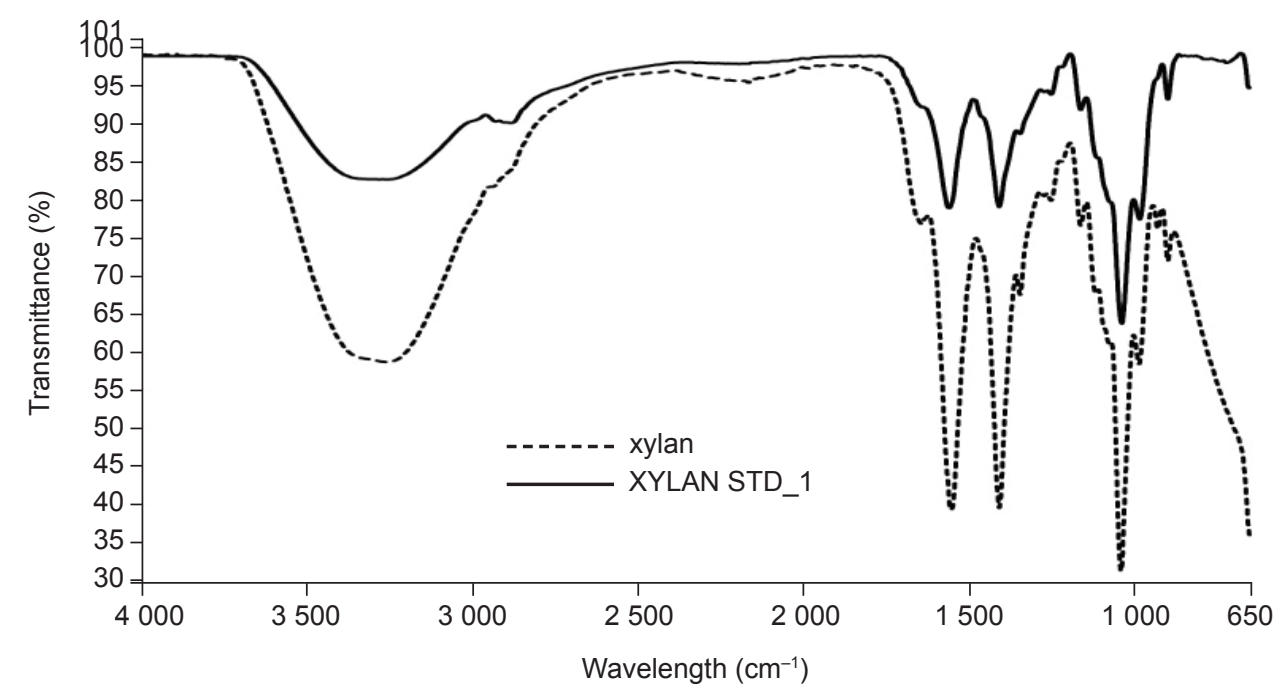

Figure 5. An overlay Fourier transform infrared (FTIR) spectrum of xylan from oil palm empty fruit bunches (OPEFB) and standard commercial xylan from beech wood (Sigma).

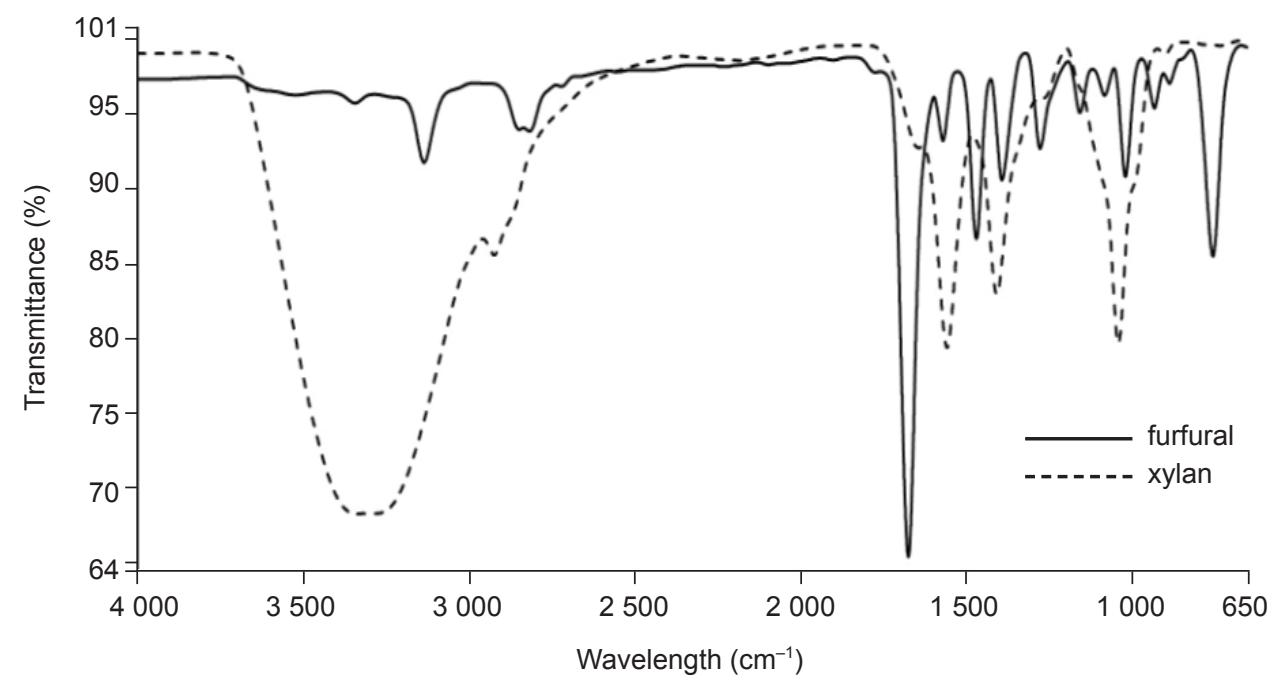

Figure 6. An overlay Fourier transform infrared (FTIR) spectrum of xylan and furfural from oil palm empty fruit bunches (OPEFB).

\section{Characterisation of Furfural by ${ }^{1} \mathrm{H}-\mathrm{NMR}$ Spectroscopy}

The ${ }^{1} \mathrm{H}-\mathrm{NMR}$ spectrum of furfural is shown in Figure 7. In this spectrum, both the individual groups and their component lines are well separated and thus the formal analysis is quite straight forward. The spectrum was separated by the coupling of the aldehyde proton to one of the ring protons. The aldehyde proton signal appears in normal low-field signal at $\delta 9.298(1 \mathrm{H})$ similar as reported by other researchers at $\delta$ 9.63-9.67 (Ismiyarto et al., 2017; Bhaumik and Dhepe 2014).

The ring protons appeared as the three groups signal in region 6.56-7.72 $\mathrm{ppm}(3 \mathrm{H})$ due to the asymmetric ring structures. On the basis of the chemical shift data, the low field signal would be expected to be that of proton 4 . Further, spin-spin coupling constants are known to be very insensitive to substitution. For example, Richards and Schaeffer (1958) have shown that the coupling constant in a series of para-substituted benzenes vary by less than $10 \%$ over a whole range of substituent groups. This again supports the assignment of the low field signal in furfural to proton 4 at $\delta 7.72(1 \mathrm{H})$. However, the spin-spin coupling between the aldehyde proton and the proton giving the low field signal would normally be expected to be between the aldehyde proton and the nearest neighbouring proton in the ring. On this basis, the low field signal in region 7.38-7.39 ppm would be assigned to proton 2 . The chemical shift data as proton 2 and proton 4 in furfural would be expected to be at lower field than hydrogen 3 due to the influence of the electronegative aldehyde group. 


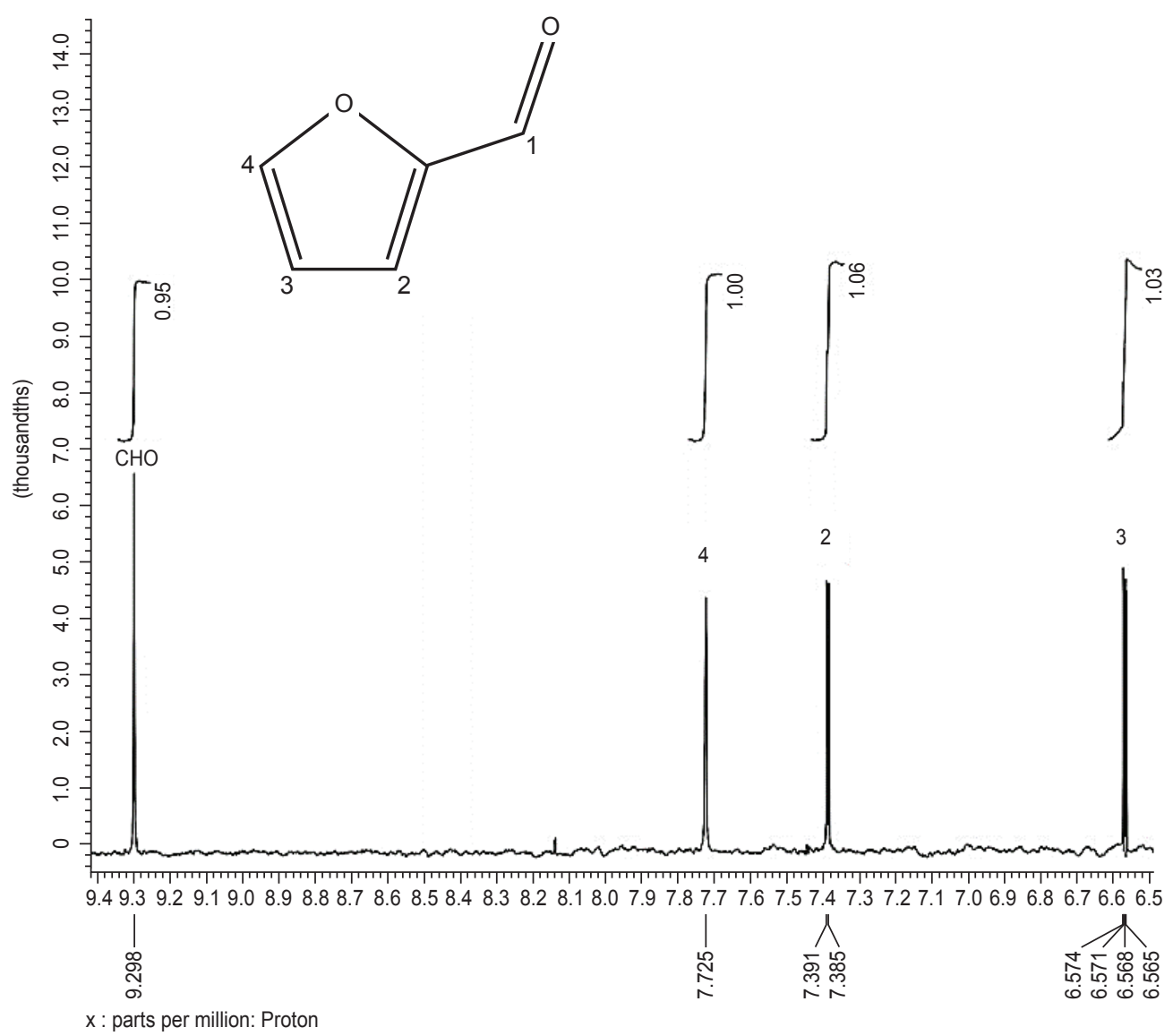

Figure 7. The Proton nuclear magnetic resonance $\left({ }^{1} \mathrm{H}-\mathrm{NMR}\right)$ spectrum of furfural dissolved in deuterium oxide $\left(\mathrm{D}_{2} \mathrm{O}\right)$.

\section{Production of Furfural from Xylan}

Hydrolysis using dilute acid is very complex, mainly because the substrate was in solid phase while the acid catalyst was in liquid phase. Results showed that the reaction parameters that influence yield of furfural production are acid concentrations, reaction time and presence of $\mathrm{NaCl}$ as promoter (Table 2). Furfural yield increased with increasing reaction time (up to $120 \mathrm{~min}$ ) (Figures $8 a$ and $8 b$ ) and $\mathrm{H}_{2} \mathrm{SO}_{4}$ concentration (up to $15 \% \mathrm{v} / \mathrm{v}$ ) (Figures $8 a$ and $8 b$ ).

The highest amount of furfural production was achived at 90 min reaction time in $\mathrm{H}_{2} \mathrm{SO}_{4}$ with or without the presence of $\mathrm{NaCl}$. The amount of furfural produced were lowest at 30 min reaction time while the yield of furfural continued to increase until $90 \mathrm{~min}$. From 90-120 min reaction times, yield of furfural produced were high, ranging from $2.99 \%-9.01 \%$. Beyond $120 \mathrm{~min}$, the furfural's yield started to decrease due to degradation to acetic acid. Gupta et al. (2009) and Mansilla et al. (1998) reported that the highest concentration of acid for steam distillation was performed with $15 \% \mathrm{H}_{2} \mathrm{SO}_{4}$ as the increment to $20 \%$ did not appear to increase furfural yield. Any further increase in acid concentration caused the increase in inhibitor release, resulting in a decrease of furfural concentration in distillate.

Furfural yields were increased with addition of $\mathrm{NaCl}$ into reaction with $\mathrm{H}_{2} \mathrm{SO}_{4}$ compared to without $\mathrm{NaCl}$ (Figure 8). The highest yield of furfural produced in the presence of $\mathrm{NaCl}$ was $9.01 \%$ which was achieved in $15 \% \mathrm{H}_{2} \mathrm{SO}_{4}$ and 90 min reaction time (Figure 8b). Meanwhile the highest yield of furfural produced without $\mathrm{NaCl}$ was about $6.63 \%$ in $15 \%$ $\mathrm{H}_{2} \mathrm{SO}_{4}$ and 120 min reaction time (Figure 8a). It was found that $\mathrm{NaCl}$ and $\mathrm{H}_{2} \mathrm{SO}_{4^{\prime}}$ which produces an inorganic salt $\mathrm{NaHSO}_{4}$ greatly improved the yield of furfural (0.8\%-2.38\%) compared to reaction with only $\mathrm{H}_{2} \mathrm{SO}_{4}$. Similar finding was reported by Yazdizadeh et al., (2016), whereby addition of $\mathrm{NaCl}$ into the reaction increased the yield of furfural by $1 \%-5 \%$.

Furfural yield in this article was lower than a reported yield from oil palm pressed fibre of $17.34 \%$ (Riansa-Ngawong and Prasertsan, 2011). This is because only pentosans (xylose and arabinose) contribute a portion of the total composition of lignocellulose to the furfural production, compared to cellulose which is the largest fraction of lignocellulosic biomass. Therefore, the integrated strategies need to be introduced or the sole production of furfural from these residues would be wasteful, inefficient and uneconomic. 
TABLE 2. AMOUNT OF FURFURAL PRODUCED IN DIFFERENT ACID CONCENTRATIONS AND WITH DIFFERENT REACTION TIMES

\begin{tabular}{|c|c|c|c|c|c|c|c|}
\hline \multirow{3}{*}{\multicolumn{2}{|c|}{ Acid concentration $\left(\mathrm{H}_{2} \mathrm{SO}_{4}\right)$}} & \multicolumn{3}{|c|}{ Without $\mathrm{NaCl}$} & \multicolumn{3}{|c|}{ With presence $\mathrm{NaCl}$} \\
\hline & & \multicolumn{6}{|c|}{ Amount of furfural $(\%)$} \\
\hline & & $11 \%$ & $13 \%$ & $15 \%$ & $11 \%$ & $13 \%$ & $15 \%$ \\
\hline \multirow[t]{5}{*}{ Reaction time (min) } & 30 & 0.42 & 0.87 & 3.27 & 3.28 & 6.83 & 7.80 \\
\hline & 60 & 1.11 & 2.31 & 5.36 & 3.37 & 7.03 & 8.03 \\
\hline & 90 & 2.80 & 5.83 & 6.07 & 3.70 & 7.70 & 9.01 \\
\hline & 120 & 3.12 & 6.49 & 6.63 & 3.92 & 8.17 & 6.67 \\
\hline & 150 & 2.72 & 5.67 & 4.70 & 2.88 & 5.99 & 5.52 \\
\hline
\end{tabular}

Note: $\mathrm{H}_{2} \mathrm{SO}_{4}$ - sulphuric acid; $\mathrm{NaCl}$ - sodium chloride.

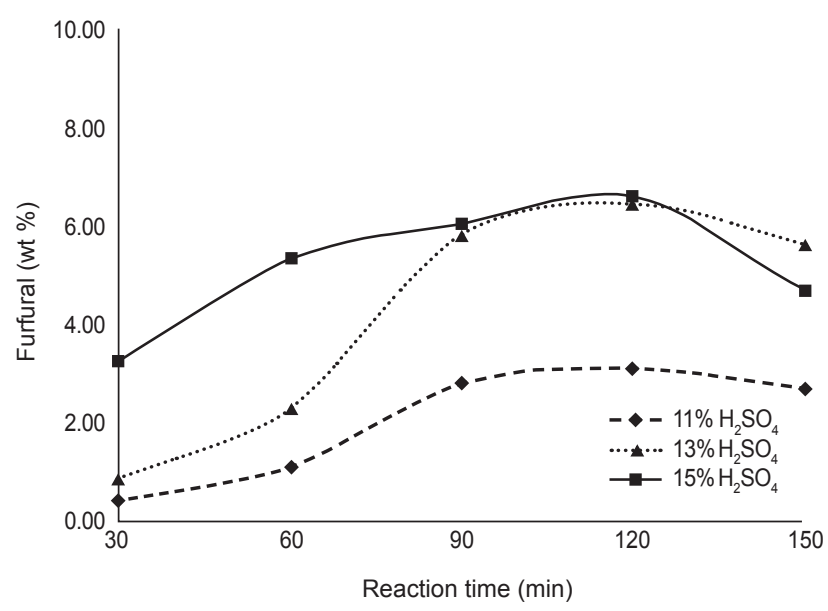

(a)

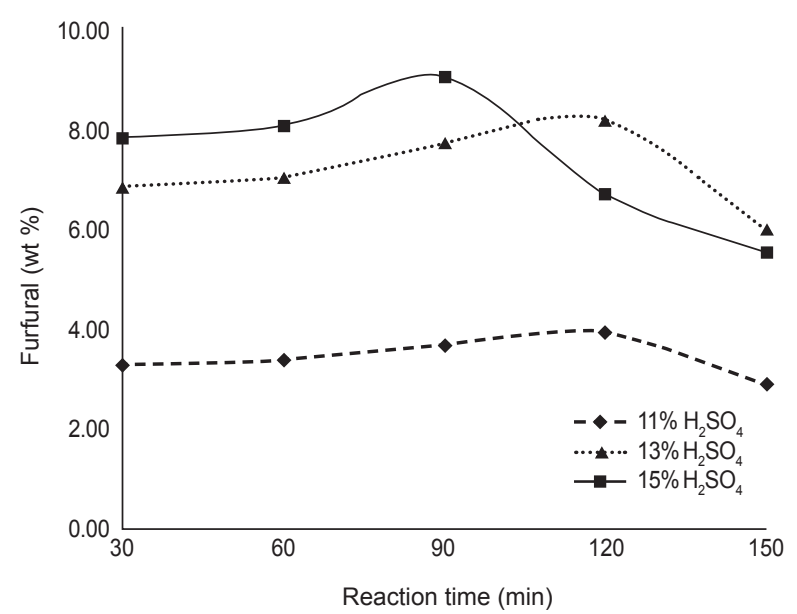

(b)

Figure 8. (a) Amount of furfural produced without sodium chloride ( $\mathrm{NaCl}$ ), and (b) with presence of $\mathrm{NaCl}$ at different reaction time in different sulphuric acid $\left(\mathrm{H}_{2} \mathrm{SO}_{4}\right)$ concentration.

\section{CONCLUSION}

Furfural was successfully extracted from OPEFB by two-step process consisted of acid hydrolysis, followed by dehydration with highest yield of $0.90 \pm 0.002 \mathrm{~g} \mathrm{litre}^{-1}$ of dry OPEFB. Xylan was extracted from OPEFB was used as substrate for furfural production. The xylan and furfural extracted were analysed using FTIR spectroscopy for structural confirmations and found to be comparable to commercial standard. The highest yield of furfural produced was $9.01 \%$ which achieved at 90 min reaction time in $15 \% \mathrm{H}_{2} \mathrm{SO}_{4}$ in the presence of $\mathrm{NaCl}$. To be economically visible, the production of furfural should be intergrated with cellulose extraction as pentoses (xylose) is just a minor portion of OPEFB chemical composition.

\section{ACKNOWLEDGEMENT}

The authors wish to thank the Director-General of MPOB for his permission to publish this article.

\section{REFERENCES}

Aguilar, R; Ramirez, J A; Garrote, G and Vazquez, M (2002). Kinetic study of the acid hydrolysis of sugar cane bagasse. J. Food Eng., 55(4): 309-318.

Alonso-Fagundez, N; Lopez Granados, M; Mariscal, $\mathrm{R}$ and Ojeda, M (2012). Selective conversion of furfural to maleic anhydride and furan with VOx $/ \mathrm{Al}_{2} \mathrm{O}_{3}$ catalysts. ChemSusChem., 5(10): 1984-1990.

ASTM (1978). Method of Test for Holocellulose in Wood-D1104-56. American Society for Testing and Materials (ASTM) International, West Conshohocken, Pennsylvania, USA.

Bamufleh, H S; Alhamed, Y A and Daous, M A (2013). Furfural from midribs of date-palm trees by sulfuric acid hydrolysis. Ind. Crops Prod., 42: 421428.

Bhaumik, P and Dhepe, P L (2014). Exceptionally high yields of furfural from assorted raw biomass over solid acids. RSC Adv., 4: 26215-26221. 
Cheung, S and Anderson, B (1996). Ethanol production from wastewater solids. Water Environ. Technol., 8(5): 55-60.

Gamez, S; Gonzalez-Cabriales, J J; Ramirez, J A; Garrote, G and Vazquez, M (2006). Study of the hydrolysis of sugar cane bagasse using phosphoric acid. J. Food Eng., 74: 78-88.

García-Domínguez, M T; García-Domínguez, J C; Feria, M J; Gómez-Lozano, D M; López, F and Díaz, M J (2013). Furfural production from Eucalyptus globulus: Optimizing by using neural fuzzy models. Chem. Eng. J., 221: 185-192.

Gupta, R; Sharma, K K and Kuhad, R C (2009). Separate hydrolysis and fermentation (SHF) of Prosopis juliflora a wood substrate, for the production of cellulosic ethanol by Saccharomyces cerevisiae and Pichia stipitis - NCIM 3498. Bioresour. Technol., 100(3): 1214-1220.

Herrera, A; Tellez-Luis, S J; Gonzalez-Cabriales, J J; Ramirez, J A and Vazquez, M (2004). Effect of the hydrochloric acid concentration on the hydrolysis of the sorghum at atmospheric pressure. J. Food Eng., 63(1): 103-109.

Herrera, A; Tellez-Luis, S J; Ramirez, J A and Vazquez, M (2003). Production of xylose from sorghum straw using hydrochloric acid. J. Cereal Sci., 37(3): 267-274.

Ismiyarto; Ngadiwiyana; Windarti, T; Purbowatiningrum, R S; Hapsari, M; Rafi'ah, F H; Suyanti and Haq, M S (2017). Synthesis of furfural from water hyacinth (Eichornia croassipes). IOP Conf. Ser.: Mater. Sci. Eng., 172(1): 012027.

Kamm, B G; Gruber, P R and Kamm, M (2006). Biorefineries Industrial Processes and Products Status Quo and Future Directions. Wiley-VCH Verlag GmbH Verlag and Co. KGaA, Weinheim, Germany.

Kushairi, A; Meilina, O; Balu, N; Elina, H; Mohd Noor Izuddin, Z B; Razmah, G; Vijaya, S; Shamala, $S$ and Ghulam Kadir, A P (2019). Oil palm economic performance in Malaysia and R\&D progress in 2018. J. Oil Palm Res., 31(2): 165-194.

Lavarack, B P; Griffin, G J and Rodman, D (2002). The acid hydrolysis of sugar cane bagasse hemicelluloses to produce xylose, arabinose, glucose and other products. Biomass Bioenerg., 23(5): 367-380.

Lenihan, P; Orozco, A; O'neill, E; Ahmad, M N M; Rooney, D W and Walker, G M (2010). Dilute acid hydrolysis of lignocelluloses biomass. Chem. Eng. J., 156(2): 395-403.
Lin, K H; Huang, M H and Chang, A C C (2013). Liquid phase reforming of rice straw for furfural production. Int. J. Hydro. Energy, 38(35): 15794.

Loi, C C; Boo, H C; Mohammed, A S and Ariffin, A A (2011). A high performance liquid chromatography method for determination of furfural in crude palm oil. Food Chem., 128(1): 223-226.

Mansilla, H D; Baeza, J; Urzua, S; Maturana, G; Villasenor, J and Duran, N (1998). Acid catalyzed hydrolysis of rice hull: Evaluation of furfural production. Bioresour. Technol., 66(3): 189-193.

Merlo, A B; Vetere, V; Ruggera, J F and Casella, M L (2009). Bimetallic PTSn catalyst for the selective hydrogenation of furfural to furfuryl alcohol in liquid-phase. Catal. Commun., 10(13): 1665-1669.

Montane, D; Salvado, J; Torras, C and Farriol, X (2002). High-temperature dilute-acid hydrolysis of olive stones for furfural production. Biomass Bioenerg., 22(4): 295-304.

Nimlos, M R; Qian, X; Davis, M; Himmel, M E and Johnson, D K (2006). Energetics of xylose decomposition as determined using quantum mechanics modeling. J. Phys. Chem. A., 110(42): 11824-11838.

O'Brien, P (2006). Furfural chemicals and biofuels from agriculture. Report for the Rural Industries Research and Development Corporation. RIRDC Publication No. 06/127. Wondu Business and Technology Services. p. 1-28.

Rahman, S H A; Choudhury, J P and Ahmad, A L (2006). Production of xylose from oil palm empty fruit bunch fibre using sulfuric acid. Biochem. Eng. J., 30(1): 97-103.

Riansa-Ngawong, W and Prasertsan, P (2010). Statistical approach for hemicellulose production from delignified palm pressed fibre and used as a bio-material for one-stage production of furfural. Int. J. Biotechnol. Biochem., 6(7): 1101-1116.

Riansa-Ngawong, W and Prasertsan, P (2011). Optimization of furfural production from hemicellulose extracted from delignified palm pressed fibre using a two-stage process. Carbohydr. Res., 346(1): 103-110.

Richards, R E and Schaeffer, T (1958). Nuclear resonance spectra of some fluorine derivatives of toluene and benzotrifluoride. Trans. Faraday Soc., 54: 1447-1453. 
Rodriguez-Chong, A; Ramirez, J A; Garrote, G and Vazquez, M (2004). Hydrolysis of sugar cane bagasse using nitric acid: A kinetic assessment. J. Food Eng., 61(2): 143-152.

Romero, I; Ruiz, E; Castro, E and Moya, M (2010). Acid hydrolysis of olive tree biomass. Chem. Eng. Res. Des., 88(56): 633-640.

Sadaba, I; Ojeda, M; Mariscal, R; Fierro, J L G and Lopez Granados, M (2011). Catalytic and structural properties of co-precipitated $\mathrm{Mg}-\mathrm{Zr}$ mixed oxides for furfural valorization via aqueous aldol condensation with acetone. Appl. Catal. B Environ., 101(3-4): 638-648.

Sánchez, C; Serrano, L; Andres, M A and Labidi, J (2013). Furfural production from corn cobs autohydrolysis liquors by microwave technology. Ind. Crops Prod., 42(1): 513-519.

Sashikala, M and Ong, H K (2007). Identification of furfural synthesized from pentosan in rice husk. J. Trop. Agric. Food Sci., 35(2): 305-312.

Shen, Y; Sun, J; Wang, B; Xu, F and Sun, R (2018). Catalytic approaches to the production of furfural and levulinates from lignocelluloses. Biomass as Renewable Raw Material to Obtain Bioproducts of HighTech Value. Elsevier. p. 235-269.

Suxia, R; Haiyan, X; Jinling, Z; Shunqing, L; Xiaofeng, H and Tingzhou, L (2012). Furfural production from rice husk using sulfuric acid and a solid acid catalyst through a two-stage process. Carbohydr. Res., 359: 1-6.

Vazquez, M; Oliva, M; Tellez-Luis, S J and Ramirez, J A (2007). Hydrolysis of sorghum straw using phosphoric acid: Evaluation of furfural production. Bioresour. Technol., 98(16): 3053-3060.

Wingren, A; Galbe, M and Zacchi, G (2003). Techno-economic evaluation of producing ethanol from softwood: Comparison of SSF and SHF and identification of bottlenecks. Biotechnol. Prog., 19(4): 1109-1117.

Yat, S C; Berger, A and Shonnard, D R (2008). Kinetic characterization for dilute sulfuric acid hydrolysis of timber varieties and switch grass. Bioresour. Technol., 99(9): 3855-3863.

Yazdizadeh, M; Jafari Nasr, M R and Safekordi, A (2016). A new catalyst for the production of furfural from bagasse. RSC Adv., 6(61): 55778-55785.

Yemis, O and Mazza, G (2011). Acid-catalyzed conversion of xylose: Xylan and straw into furfural by microwave-assisted reaction. Bioresour. Technol., 102(15): 7371-7378.

Zhang, H; Ping, Q; Zhanga, J and Li, N (2017). Determination of furfural and hydroxymethyl furfural by UV spectroscopy in ethanol-water hydrolysate of reed. J. Bioresour. Bioprod., 2(4): 170174. 